\title{
Metastatic cutaneous breast carcinoma: A case report and review of the literature
}

\author{
Guillermina Nava $M D^{1}$, Kenneth Greer $\mathrm{MD}^{2}$, James Patterson $\mathrm{MD}^{3}$, Kant $\mathrm{Y}$ Lin $M D^{1}$
}

\begin{abstract}
G Nava, K Greer, J Patterson, KY Lin. Metastatic cutaneous breast carcinoma: A case report and review of the literature. Can J Plast Surg 2009;17(1):25-27.

Cutaneous metastatic carcinoma, also known as carcinoma erysipeloides, is an unusual clinical finding. In women, it is most frequently found in association with breast cancer rather than other visceral malignancies. Breast cancer patients can present with cutaneous manifestations of breast disease at the time of their initial diagnosis; however, cutaneous metastases more often present well after the initial diagnosis and treatment of the breast disease. Prompt recognition of skin metastases by the plastic surgeon, especially during the delayed setting of reconstructive surgery following mastectomy, allows for earlier intervention in treating the systemic spread of the disease. A clinical case of carcinoma erysipeloides presenting in this delayed setting is outlined in the present report, along with a review of the literature.
\end{abstract}

Key Words: Breast cancer; Carcinoma erysipeloides; Cutaneous metastases

$\mathrm{C}$ Yutaneous metastatic carcinoma is an unusual clinical finding. Review of the literature indicates that the incidence of cutaneous metastases for all types of carcinomas ranges from $0.7 \%$ to $10.0 \%(1-3)$. Similarly, a more recent meta-analysis (4) demonstrated the overall incidence to be closer to $5.3 \%$. Metastatic cutaneous lesions are more often found in women with breast cancer, than in those with other visceral malignancies, with an incidence exceeding 20\% (3-6). Often, the cutaneous lesions do not become apparent until quite some time has passed from the initial treatment of the original carcinoma. In light of the current trend among plastic surgeons to perform breast reconstruction immediately following mastectomy, it becomes incumbent on clinicians caring for breast cancer patients to appreciate the incidence of cutaneous manifestations, and to be able to accurately and immediately identify this clinical entity in all its forms. Only with prompt recognition comes the opportunity to treat the systemic spread of the cancer in as early a stage as possible to improve survival rates.

\section{CASE PRESENTATION}

A 51-year-old Caucasian woman with a history of right-sided T3c N2 breast cancer underwent a modified radical mastectomy in March 2003 followed by chemotherapy and radiation therapy. She then underwent breast reconstruction with a delayed pedicled transverse rectus abdominis myocutaneous flap in October 2003. She returned to the plastic surgery clinic in February 2006 for evaluation for possible nipple

\section{Un carcinome cutané métastatique du sein : Un rapport de cas et une analyse bibliographique}

Le carcinome cutané métastatique, ou carcinome érysipéloïde, est une observation clinique inhabituelle. Chez les femmes, il s'associe plutôt au cancer du sein qu'aux autres tumeurs malignes viscérales. Les patientes atteintes du cancer du sein peuvent présenter des manifestations cutanées de ce cancer au moment du diagnostic. Cependant, les métastases cutanées font beaucoup plus souvent leur apparition bien après le diagnostic initial et le traitement de la maladie cancéreuse. Un dépistage rapide des métastases cutanées par le chirurgien plastique, notamment dans le cadre reporté de la chirurgie reconstructive après une mastectomie, permet une intervention plus rapide pour éviter la propagation systémique de la maladie. Le présent rapport expose un cas clinique de carcinome érysipéloïde, de même qu'une analyse bibliographique dans un tel contexte.

Departments of ${ }^{1}$ Plastic Surgery, ${ }^{2}$ Dermatology and ${ }^{3}$ Pathology, University of Virginia Health Systems, Charlottesville, Virginia, USA

Correspondence: Dr Kant Y Lin, Department of Plastic and Reconstructive Surgery, University of Virginia Health Sciences Center,

PO Box 800376, Charlottesville, Virginia 22903, USA. Telephone 434-924-2528, fax 434-924-5801, e-mail kyl5s@virginia.edu 


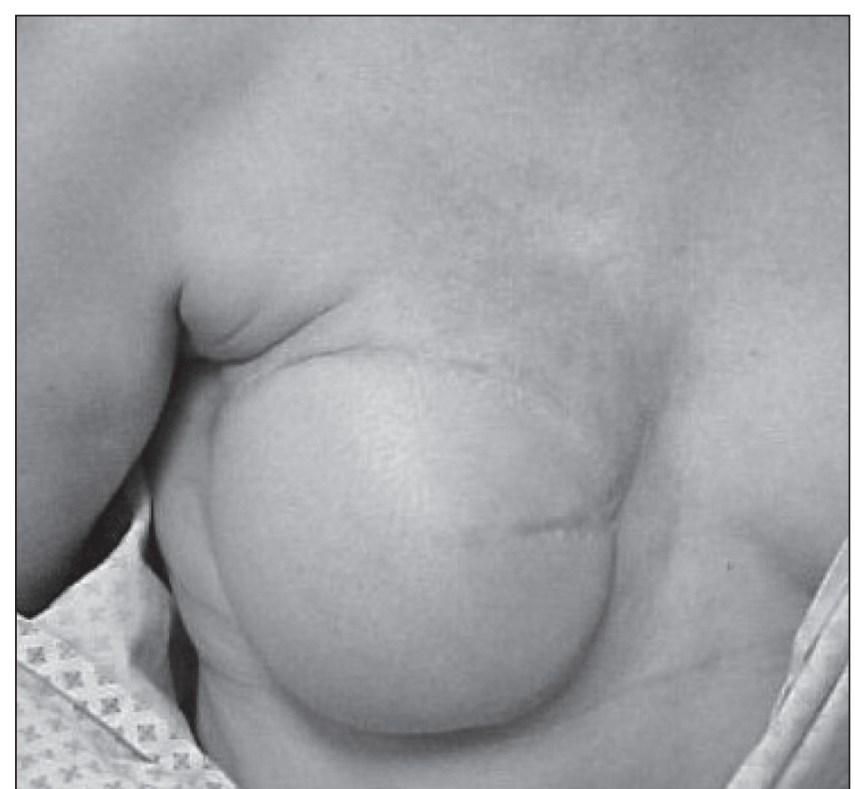

Figure 1) Erythematous macular-papular rash with induration along the upper inner quadrant of the native breast skin adjacent to the flap

Histological evaluation of the biopsy specimen was performed. Dysplastic cells were seen predominantly growing within superficial and deep dermal lymphatic vessels, with morphological features resembling those of inflammatory breast carcinoma (Figure 2). Pathological diagnosis was given as "recurrent or metastatic breast carcinoma".

With this diagnosis, the patient returned to her medical oncologist and was started on systemic chemotherapy, consisting of Paclitaxel and Trastuzumab. Follow-up at two months showed that her skin changes had significantly improved, with near eradication of the rash.

\section{DISCUSSION}

Breast cancer continues to be the second most common cancer among women, after nonmelanoma skin cancer, with a lifetime risk of $13 \%$ (7). Many women with breast cancer will elect to proceed with breast reconstruction following surgical removal of the diseased breast. Whether autologous tissue or implant reconstruction is performed, and whether done in an immediate or delayed fashion, these patients may be followed by a plastic surgeon for several years following their initial diagnosis. This is especially true if they pursue secondary aspects of their reconstruction such as nipple reconstruction, contralateral breast reduction, tattooing and so forth. Although the incidence of cutaneous metastases from all carcinomas is rare, it has been shown that it is mostly found among women with breast cancer. In an autopsy series of 7518 patients with visceral malignancy, $26.5 \%$ of women with breast cancer were found to have cutaneous metastases (3). A subsequent metaanalysis (4) confirmed this incidence of skin metastasis in breast cancer to be approximately $23.9 \%$. These numbers are far in excess to those cited for other visceral malignancies. Therefore, the ability of reconstructive surgeons of the breast to identify cutaneous metastases accurately and immediately can result in earlier diagnosis and therefore earlier treatment for their patients.

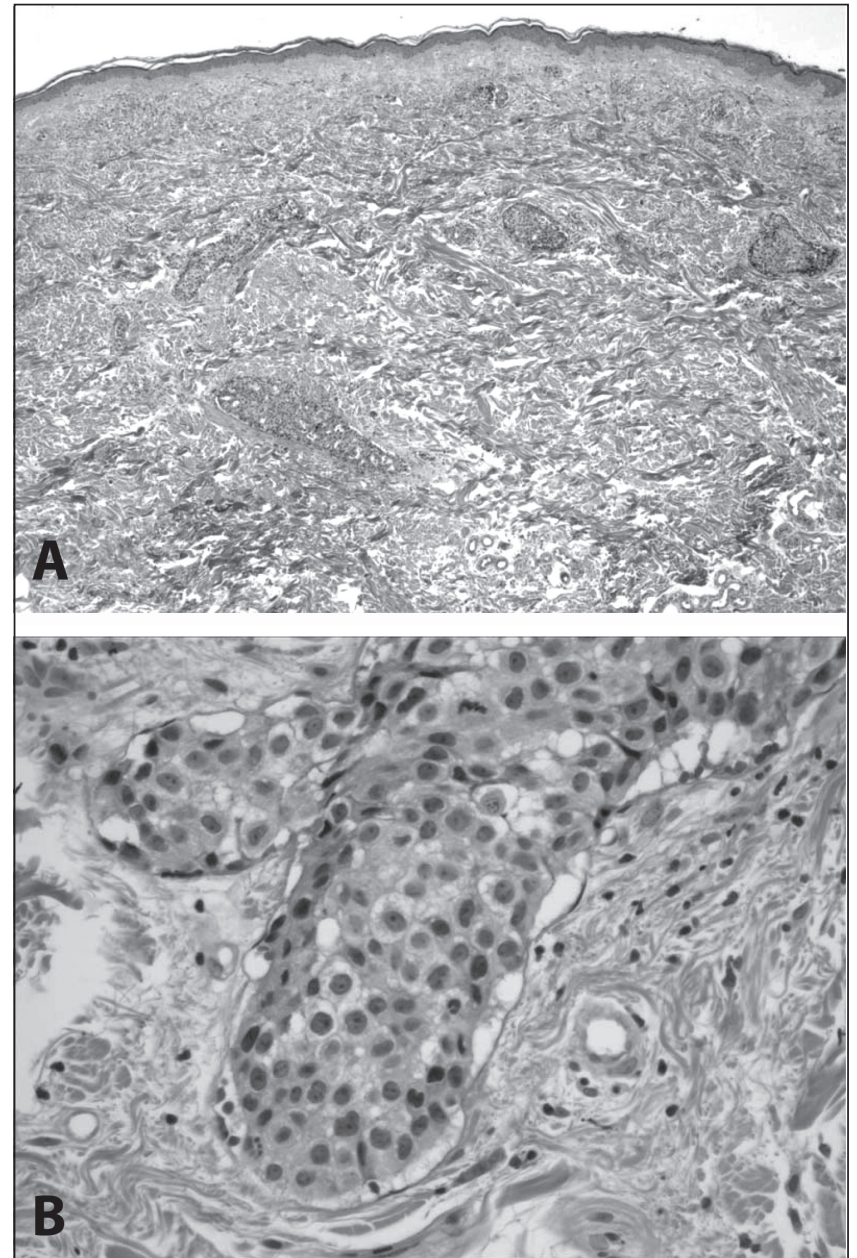

Figure 2) Low- and high-power views of inflammatory carcinoma of the breast. A At low magnification, discrete islands of tumour cells are identified within the dermis; B At higher magnification, neoplastic cells can be seen to occupy lymphatic vessels lined by thin layers of endothelium

The differential diagnoses of cutaneous lesions are varied. In a breast cancer patient, other possible etiologies besides cutaneous metastases include cutaneous change, either acute or chronic - secondary to radiation therapy - or other infectious processes such as erysipelas, cellulitis or candidiasis. A physician caring for breast cancer patients must be able to distinguish between these. In the present patient, an infectious process was considered, but the clinical picture and history did not completely support this diagnosis. In general, specific clinical features such as lack of a febrile response, absence of leukocytosis and prolonged presence of the lesion (weeks to months) without response to antibiotics should alert the physician to the possibility of cutaneous metastasis (8).

Inflammatory breast carcinoma is an unusual but distinct form of cutaneous metastases. It was originally described in 1924 in a review of 28 cases of breast cancers associated with inflammatory skin changes (9). These skin changes, characterized by red induration with distinctly marginated borders associated with skin metastases, were later described as "carcinoma erysipelatoides" by Rasch in 1931 (10) for their similarity to the infectious skin condition erysipelas (Figure 3). Thus, both terms, inflammatory carcinoma and carcinoma erysipeloides, have been used interchangeably when describing skin metastases with 
inflammatory skin changes and histological invasion of dermal lymphatics $(6,8,11-15)$.

In a recent retrospective review by Mordenti et al (2), 164 cases of skin metastases specifically from breast carcinoma were examined to determine the most common clinical and histopathological presentations. Skin papules and/or nodules were found in $80 \%$ of patients, telangiectatic carcinomas in $11 \%$, erysipeloid carcinomas in 3\%, 'en cuirasse' carcinomas in $3 \%$, alopecia neoplastica in $2 \%$ and a zosteriform type in $0.8 \%$ (2).

Clinical features were also evaluated in a retrospective study of 89 patients with inflammatory breast carcinoma. Clinical features included erythema in $51 \%$, a palpable breast mass in $51 \%$, breast enlargement in $43 \%$ and, less frequently, increased warmth, edema, nipple retraction and itching. The inflammatory skin changes started, on average, 10 weeks before diagnosis (16).

Other clinical and pathological varieties of cutaneous metastases from breast carcinoma also exist. Nodular metastatic carcinomas can present as firm, solitary or multiple skin masses or lumps $(17,18)$. This form can also be accompanied by pigmentation or irregular borders, which is suggestive of melanoma or pigmented basal cell carcinoma (17). Histologically, they appear as atypical neoplastic cells arranged in small nests, islands or cords in single-file within the collagen bundles of the dermis (15). En cuirasse metastatic carcinoma is rare, and usually begins as scattered, firm, lenticular papulonodules over an erythematous or red-blue smooth cutaneous surface. The nodules form a sclerodermoid plaque with no inflammatory changes (17). Another form, telangiectatic metastatic carcinoma, is characterized by its purple colour due to blood in the dilated vascular channels. The lesions are papulovesicles appearing over an erythematous surface similar to inflammatory metastatic carcinoma. Patients often complain of intense

\section{REFERENCES}

1. Lookingbill DP, Spanger N, Helm KF. Cutaneous metastases in patients with monastic carcinoma: A retrospective study of 4020 patients. J Am Acad Dermatol 1993;29:228-36.

2. Mordenti C, Peris K, Concetta Fargnoli M, Cerroni L, Chimenti S. Cutaneous metastatic breast carcinoma. Acta dermatovenerologica 2000;9. <www.mf.uni-lj.si/acta-apa/acta-apa-00-4/mordenti.html> (Verson current at July 21, 2008).

3. Spencer PS, Helm TN. Skin metastases in cancer patients. Cutis 1987;39:119-21.

4. Krathen RA, Orengo IF, Rosen T. Cutaneous metastasis: A metaanalysis of data. South Med J 2003;96:164-7.

5. Brownstein MH, Helwig EB. Metastatic tumors of the skin. Cancer 1972;29:1298-307.

6. Brownstein MH, Helwig EB. Patterns of cutaneous metastases. Arch Dermatol 1972;105:862-8.

7. American Cancer Society. Breast Cancer Facts \& Figures 20052006. Atlanta: American Cancer Society, Inc.

8. Hazelrigg DE, Rudolph AH. Inflammatory metastatic carcinoma. Arch Dermatol 1977;113:69-70.

9. Lee BJ, Tannenbaum NE. Inflammatory carcinoma of the breast: A report of twenty-eight cases from the breast clinic of the Memorial Hospital. Surg Gynecol Obstet 1924;39:580.

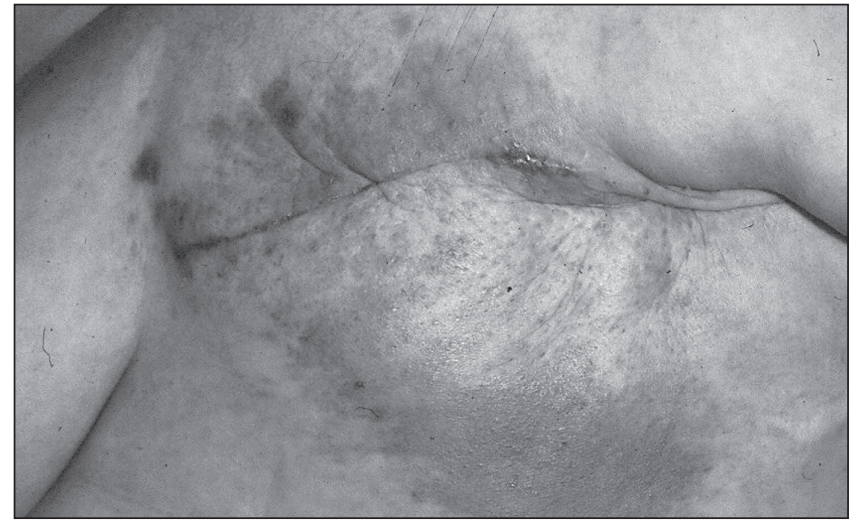

Figure 3) Classic representation of carcinoma erysipeloides. Patient status post left mastectomy with subsequent development of erythematous patch at mastectomy site

pruritis (17). Alopecia neoplastica is believed to be caused by hematogenous spread and appear as circular areas of alopecia on the scalp. The firm area of scalp skin associated with hair loss can be confused with alopecia areata; however, on palpation, alopecia neoplastica has marked induration (17).

When planning reconstructive options for breast cancer patients, the chest, abdomen and back regions are important areas for evaluation by the plastic surgeon. These exact areas correspond to and mirror the locations where cutaneous breast metastases of all types are most commonly seen $(2,4-6)$. Therefore, it is often the plastic surgeon following the breast cancer patient during the reconstructive phases of their treatment plan, long after the initial treatment of their breast disease, who is in the best position to identify and initiate early treatment of cutaneous metastases.

10. Rasch C. Carcinoma erysipelatoides. Br J Dermatol Syph 1931;43:351-4.

11. Ruiz De Erenchum F, Vazquez Doval J, Valerdiz S, Serna MJ, Quintanilla E. Inflammatory metastatic carcinoma. J Dermatol Surg Oncol 1991;17:784-7.

12. Cox SE, Cruz PD. A spectrum of inflammatory metastasis to skin via lymphatics: Three cases of carcinoma erysipeloides. J Am Acad Dermatol 1994;30:304-7.

13. Lever LR, Holt PJA. Carcinoma erysipeloides. Br J Dermatol 1991;124:279-82.

14. Finkel LJ, Griffiths CE. Inflammatory breast carcinoma (carcinoma erysipeloides): An easily overlooked diagnosis. Br J Dermatol 1993;129:324-6.

15. Healey PM, Malott IK, Chalet MD. Cancers metastatic to the skin. In: Friedman RJ, Rigel DS, Harris MN, Baker D, eds. Cancer of the Skin. Philadelphia: WB Saunders; 1991:347-63.

16. Haagensen CD, ed. Diseases of the Breast. Philadelphia: WB Saunders, 1971:576-84.

17. Schwartz RA. Cutaneous metastatic disease. J Am Acad Dermatol 1995;33:161-82.

18. Pakula A. Recognizing malignant skin changes following breast cancer. Am Fam Physician 1992;45:1287-92. 
